\title{
Micro-Fabric Transformations of Ball Clay in Alkaline Environment
}

\author{
V. Sai Kumar $\dagger$, P. Hari Prasad Reddy and Ch. Rama Vara Prasad \\ Department of Civil Engineering, GITAM Institute of Technology, GITAM (Deemed to be University), \\ Visakhapatnam, Andhra Pradesh, India \\ $†$ Corresponding author: Sai Kumar Vindula; svindula@gitam.edu
}

Nat. Env. \& Poll. Tech.

Website: www.neptjournal.com

Received: 25-10-2020

Revised: $05-01-2021$

Accepted: 13-01-2021

Key Words:

Ball clay

$\mathrm{NaOH}$

Transmutation

XRD and SEM

\section{ABSTRACT}

Based on the strong evidence of case histories, this study focused on mineralogical and morphological changes of an artificial kaolinitic soil -Ball clay, when exposed to different concentrations of sodium hydroxide $(0.1 \mathrm{~N}, 1 \mathrm{~N}, 4 \mathrm{~N}$, and $8 \mathrm{~N})$ under different curing periods $(7,28$ and 100 days). Sediment volume tests are conducted on Ball clay with all combinations and results are analyzed with the help of analytical techniques. XRD and SEM studies are analyzed to understand the micro-level changes of alkali contaminated Ball clay. Mineralogical and morphological transmutations of Ball clay are investigated for 7,28 , and 100 days curing period. Results revealed new mineral formations like Sodalite under $4 \mathrm{~N}$ and $8 \mathrm{~N}$ concentrations of $\mathrm{NaOH}$ with 100 days interactions are well observed. The morphological transformation from needle shape to pellet shape is clear evidence of the rate of dissolution and precipitation of minerals under 100 days curing periods.

\section{INTRODUCTION}

Soil pollution occurs from a broad range of sources which includes over usage of chemicals and accidental spillovers (Ibrahim 2004). All types of soil have direct or indirect, short-term or long-term effects on the soil behavior, which leads to partial or complete transport of contaminants into the ground. The Scientific-Research Institute of Foundations and Underground Structures has investigated the physical and chemical reactions which take place between clayey minerals and acids and alkalis (Sokolovich 1995). In recent years, the detrimental failures of industrial structures are mostly associated with contamination of foundation soils with either acids or alkalis, and alkali contamination has a significant effect on the soil (Sokolovich \& Troitskii 1976, Sibley \& Vadgama 1986, Rao \& Rao 1994, Assa'ad 1998).

Sokolovich \& Troitskii (1976) reported the heaving of sand due to leakage of $\mathrm{NaOH}, \mathrm{NH} 4 \mathrm{Cl}$, and soda solutions into the subsoil for five year period of the Krasnopresensk sugar refinery in Moscow. Chunikhin et al. (1988) observed swelling of alkali-saturated soil depends on the gradation, mineral composition, and the amount of clayey fraction contained in the ground. Sivapullaiah et al. (2004) presented the structural distortion of buildings in an alumina extraction plant, Karnataka, India, caused by prolonged contamination with alkali, which led to the heaving of subsoil.

Interaction of clay minerals under highly alkaline conditions results in dissolution and precipitation (Elert et al. 2005,
Taubald et al. 2000, Bauer \& Velde 1999, Bauer \& Berger 1998, Cuadros \& Linares 1996). From the existing literature, it is well-known that transformations of clay minerals depend on the type of the reacting mineral, its chemical composition, and the concentration of the alkaline solutions. Based on the literature on mineral transformations, it was concluded that under high alkaline conditions, dissolution of primary and secondary minerals results in the formation of new minerals which belongs to the family of zeolites Studies revealed, natural expansive and non-expansive soils under different alkali contaminations significantly affect the engineering properties of soil. Hence in this study, artificially available Ball clay with the same mineral composition with different proportions has been considered. Different concentrations $(0.1 \mathrm{~N}, 1 \mathrm{~N}, 4 \mathrm{~N} \& 8 \mathrm{~N})$ of sodium hydroxide for alternate curing periods (7,28 \& 100days).

\section{MATERIAL AND METHODS}

\section{Ball Clay}

Ball clay known as 'plastic clay' originated from sedimentary rocks becomes highly plastic under moist conditions. Ball clay exhibits highly variable compositions (Table 1) with kaolinite as a predominant mineral along with quartz and mica. A typical Ball clay powder is light grey or cream color in appearance and is extensively used in the field of ceramics. Commercially available Ball clay has been purchased from Godavari Mines and Minerals, Visakhapatnam, Andhra 
Table 1: Physical properties of Ball Clay.

\begin{tabular}{|ll|}
\hline Property & Value \\
\hline Specific Gravity & 2.6 \\
Liquid Limit \% & 49 \\
Plastic Limit \% & 29 \\
Plasticity Index \% & 20 \\
Clay & 36 \\
Silt & 64 \\
Soil Type & $\mathrm{CI}$ \\
Cation Exchange Capacity meq/100g & 6.4 \\
Max. Dry Density KN/m ${ }^{3}$ & 16.6 \\
Optimum Moisture Content \% & 24.5 \\
\hline
\end{tabular}

Pradesh, India. Lumps forms of Ball clay are oven-dried for moisture removal and pulverized in the laboratory. Finally, the soil was allowed to pass through no. $40(425 \mu)$ sieve before making it useful.

\section{Preparation of Sodium Hydroxide (NaOH) Solutions}

Sodium hydroxide, also known as Lye and caustic soda and is commercially available in pellets form, is purchased from Fisher scientific and the required concentration of solutions using distilled water is prepared. Being deliquescent, $\mathrm{NaOH}$ readily absorbs moisture from the air, and hence it is stored in an airtight container. The author prepared Sodium hydroxide solutions of $0.1 \mathrm{~N}, 1 \mathrm{~N}, 4 \mathrm{~N}$, and $8 \mathrm{~N}$ by dissolving $4 \mathrm{~g}, 40 \mathrm{~g}$, $160 \mathrm{~g}$, and $320 \mathrm{~g}$ of analytical grade sodium hydroxide pellets with distilled water in glass bottles. As the solution liberates heat, it is placed in a water bath to maintain an average room temperature. The bottles are closed to avoid evaporation. Later the solution is transferred into a volumetric flask and makes up to $1 \mathrm{~L}$ with distilled water (ASTM E 200-08 2008).

\section{Sediment Volume Test}

The author followed the procedure established by Rao \& Sridharan (1985) for determining the sediment volume test (Fig. 1) by considering the limitations of the test method proposed by Holtz and Gibbs. The soil samples which are more vulnerable to alkali attack with a more specific surface area were sieved through $75 \mu \mathrm{m} .10 \mathrm{~g}$ of Ball clay with 40 $\mathrm{mL}$ of distilled water with the required alkali concentration solution in $100 \mathrm{~mL}$ graduated cylinders is mixed initially. The suspension is then thoroughly and repeatedly stirred. The sample is allowed to equilibrate for 24 hours to ensure thorough wetting. Suspensions are made up to $100 \mathrm{~mL}$ with distilled water and closed with caps. The graduated cylinders are left undisturbed for 24 hours duration for significant equilibrium and volume in terms of cc.gm ${ }^{-1}$ is noted respectively. The supernatant from every cylinder is drained after the completion of sufficient curing periods $(7,28$, and 100 days). All wet samples are collected in containers and allowed to dry until the moisture gets vanished. The soil samples were ground into a fine powder, moisture-free to make them fit for X-Ray diffraction (XRD) and Scanning Electron Microscopy (SEM) analysis.

Samples are analyzed from $6^{\circ} 2 \theta$ to $70^{\circ} 2 \theta /$, at a step size of 0.017 , using copper $\mathrm{k}$ alpha radiation, X-Ray Diffractometer, PANalytica, and Netherland. X-Ray diffraction patterns are obtained for the chemical mixed soil

Table 2: Chemical composition of soils.

\begin{tabular}{|llllllllll|}
\hline Soil & $\mathrm{SiO}_{2}$ & $\mathrm{Al}_{2} \mathrm{O}_{3}$ & $\mathrm{Fe}_{2} \mathrm{O}_{3}$ & $\mathrm{MgO}$ & $\mathrm{CaO}$ & $\mathrm{Na}_{2} \mathrm{O}$ & $\mathrm{K}_{2} \mathrm{O}$ & $\mathrm{Ti}_{2} \mathrm{O}$ & $\mathrm{MnO}^{2}$ \\
\hline Ball Clay & 44.4 & 35.3 & 11.8 & 2.1 & 2.7 & 0.04 & 0.41 & 1.97 & 0.2 \\
\hline
\end{tabular}

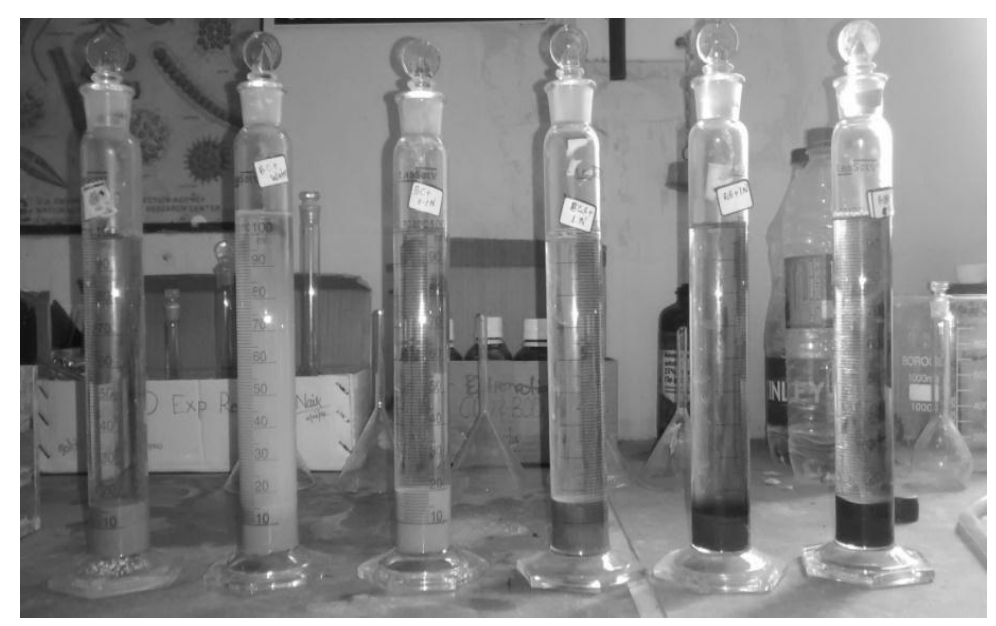

Fig. 1: Sediment Volume Test. 
Table 3: Quantification of Sediment Volume Test (mL).

\begin{tabular}{|llllll|}
\hline $\begin{array}{l}\text { Exposure Period } \\
\text { (in days) }\end{array}$ & $\begin{array}{l}\text { Distilled } \\
\text { water }\end{array}$ & $0.1 \mathrm{~N}$ & $1 \mathrm{~N}$ & $4 \mathrm{~N}$ & $8 \mathrm{~N}$ \\
\hline 1 & 11 & 27 & 23 & 26 & 30 \\
7 & 12 & 27 & 23 & 25 & 20 \\
28 & 12 & 26 & 23 & 25 & 18 \\
100 & 13 & 28 & 26 & 37 & 32 \\
\hline
\end{tabular}

specimens to detect the formation of any new compounds due to the chemical reaction with the soil mineral. SEM is employed for characterizing and examining the morphology of soil samples. SEM-TESCAN was the model used for the present study. A small oven-dried sample is glued to the SEM stub along with the gold-coated sputter before scanning. SEM images under $2 \mu \mathrm{m}, 5 \mu \mathrm{m}$, and $10 \mu \mathrm{m}$ are considered for the identification of morphological changes.

\section{X-Ray Fluorescence Spectrometer (XRF) Test}

The chemical composition of clay was evaluated with the help of X-Ray Fluorescence (XRF) spectroscopy technique. Phillips PW 2404 X-Ray fluorescence spectrometer was used for XRF analysis. About $5 \mathrm{~g}$ of dried soil sample finer than $20 \mu$ is placed on glass holders and scanned to obtain the chemical composition (Table 2).

\section{RESULTS AND DISCUSSION}

Quantification of sediment volume test in Table 3 marked all abnormal changes in terms of swelling behavior occurred in Ball clay exposure to different concentrations of $\mathrm{NaOH}$ under various curing periods. Original Ball clay exhibited different mineralogical and morphological changes when exposed to $0.1 \mathrm{~N}, 1 \mathrm{~N}, 4 \mathrm{~N}$, and $8 \mathrm{~N}$ under different curing periods of 7, 28, and 100 days. Results under XRD studies clearly highlighted the primary quartz (peaks at 4.25, 3.34, 1.82 , and $1.37[\AA ̊])$ ) along with kaolinite (major peaks at 7.14, $4.45,3.57,2.55$, and $2.38[\AA]$ ) as their major minerals. The micrograph of Ball clay from SEM studies showed fibrous microstructure with layered needle morphology.

\section{Mineralogical Changes of Ball Clay under 7 Days Interactions Period}

XRD patterns of Ball clay with different concentrations of $0.1 \mathrm{~N}, 1 \mathrm{~N}, 4 \mathrm{~N}$, and $8 \mathrm{~N} \mathrm{NaOH}$ solutions under a constant curing period of 7 days are highlighted in Fig. 2. The commercially available Ball clay primarily consists of quartz (Peaks at 4.25, $3.34,1.82$, and $1.37[\AA]$ ) and kaolinite (Peaks at 7.14, 4.45, $3.57,2.49$, and $2.38[\AA]$ ) as their major minerals. No noticeable changes are observed in the XRD patterns of Ball clay under all concentrations of $\mathrm{NaOH}$ solutions as it is not inclined towards the dissolution process of kaolinite minerals.

\section{Morphological Changes of Ball Clay (BC) under 7 Days Interaction period}

Stratified needle form morphology of Ball clay remained unchanged under 7 days of interaction period though the concentration of $\mathrm{NaOH}$ was increased to $8 \mathrm{~N}$ (Fig. 3).

\section{Mineralogical Changes of Ball Clay under 28 Days Interactions Period}

Ball clay with its mineralogical transformations is clearly highlighted in Fig.4. Quartz (Peaks at 4.25, 3.34, 1.82, and $1.37[\AA])$ along with kaolinite (Peaks at 7.14, 4.45, 3.57, 2.49 , and $2.38[\AA])$ are identified as their major minerals.

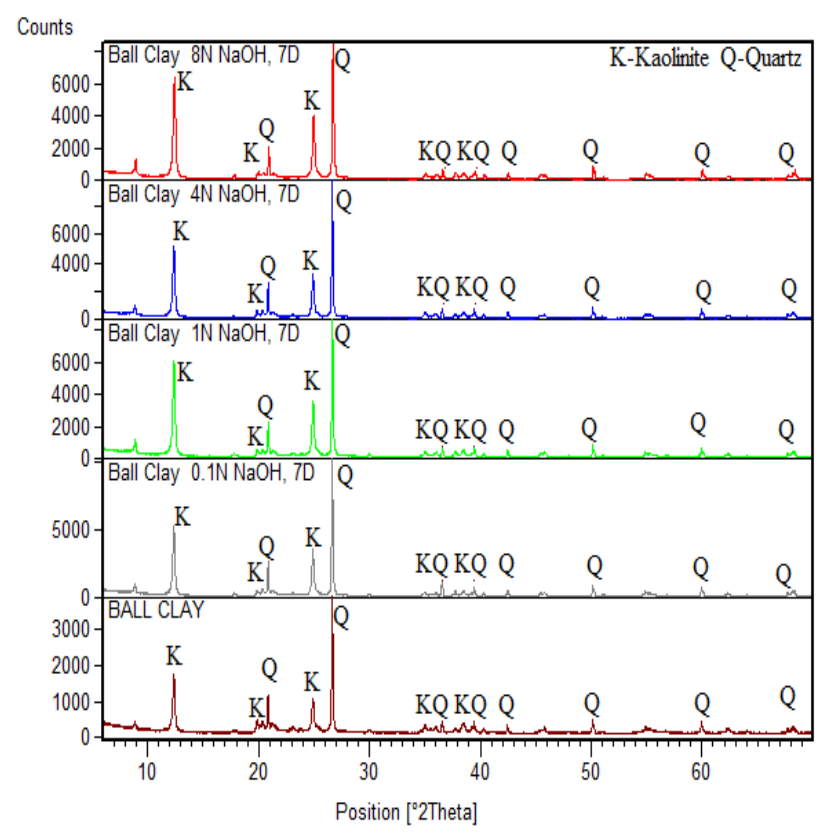

Fig. 2: XRD pattern of Ball clay under 7 days interaction.

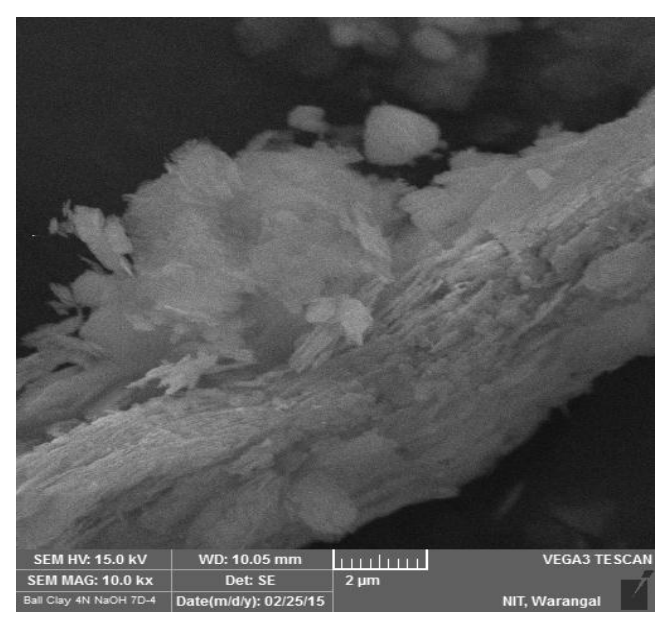

Fig. 3: SEM image of Ball clay under 7 days interaction. 


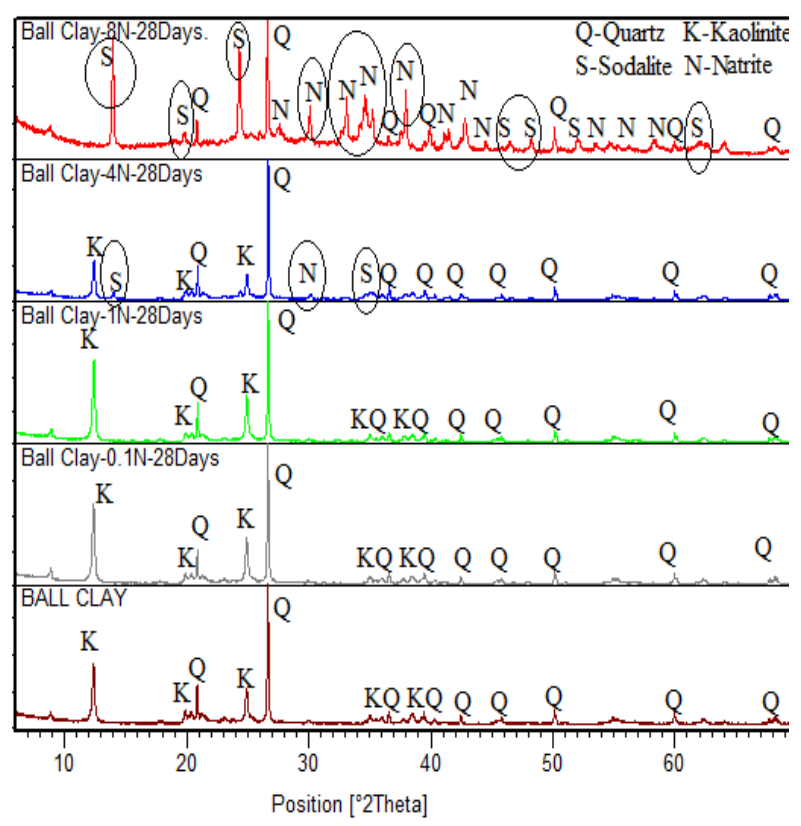

Fig. 4: XRD pattern of Ball clay under 28 days interaction.

No changes are observed in the XRD pattern of soil when it interacts with $0.1 \mathrm{~N}$ and $1 \mathrm{~N} \mathrm{NaOH}$ solutions for 28 days. The reaction of Ball clay with $4 \mathrm{~N} \mathrm{NaOH}$ leads to the formation of new peaks of sodalites $(6.34,3.66$, and 2.82 $[\AA])$, which belong to the zeolite family. Formations of natrite (sodium carbonate) peaks at 3.23, 2.96, 2.71, and 2.62[^] are also identified. Further increase in the concentration of $\mathrm{NaOH}$ to $8 \mathrm{~N}$, triggered the formations of sodalites and natrites with more intensities. Complete dissolution of kaolinite minerals is well observed from the XRD studies and confirms the transformation of kaolinite to zeolitic minerals under $4 \mathrm{~N}$ and $8 \mathrm{~N} \mathrm{NaOH}$ solutions.

\section{Morphological Changes of Ball Clay under 28 Days Interaction Period}

No textural changes were observed in Ball clay when it interacts with $0.1 \mathrm{~N}$ and $1 \mathrm{~N} \mathrm{NaOH}$ concentrations. However, morphological changes were observed with disintegrated structures when exposed under $4 \mathrm{~N}$ and $8 \mathrm{~N} \mathrm{NaOH}$ concentrations. A cubic crystalline formation with a weathered texture was identified under $4 \mathrm{~N} \mathrm{NaOH}$ conditions. Compacted pellets with cotton Ball-type morphology are observed when Ball clay interacts with $8 \mathrm{~N} \mathrm{NaOH}$, which is a typical morphology exhibited by sodalite (Barnes et al. 1999). The open structural formations further confirm the new mineral, which belongs to the zeolite family (Fig. 5).

\section{Mineralogical Changes of Ball Clay under 100 Days Interaction Period}

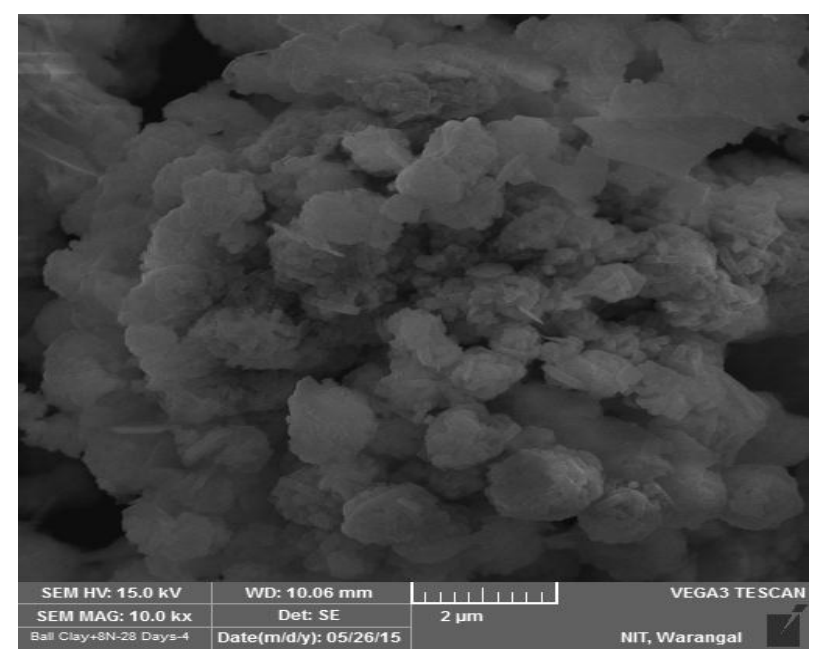

Fig. 5: SEM image of Ball clay under 28 days interaction.

Fig. 6 revealed the variations in XRD patterns of Ball clay when it interacts with $0.1 \mathrm{~N}, 1 \mathrm{~N}, 4 \mathrm{~N}$, and $8 \mathrm{~N} \mathrm{NaOH}$ solution for 100 days in comparison with uncontaminated soil. No changes are observed in the XRD patterns of Ball clay when it interacts with $0.1 \mathrm{~N} \mathrm{NaOH}$ solutions for 100 days. Subsequently, with $1 \mathrm{~N} \mathrm{NaOH}$, the intensity of kaolinite peaks is reduced due to its dissolution. The silica and alumina released from the dissolution process react with sodium ions under high alkali conditions leading to the formation of new

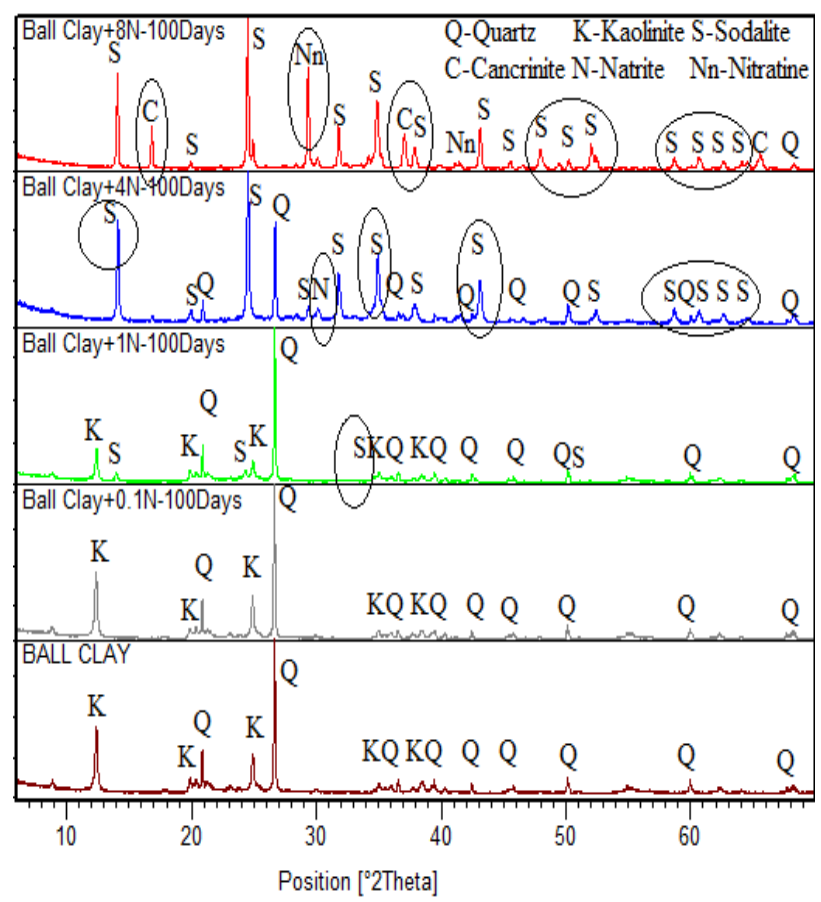

Fig. 6: XRD pattern of Ball clay under 100 days interaction. 


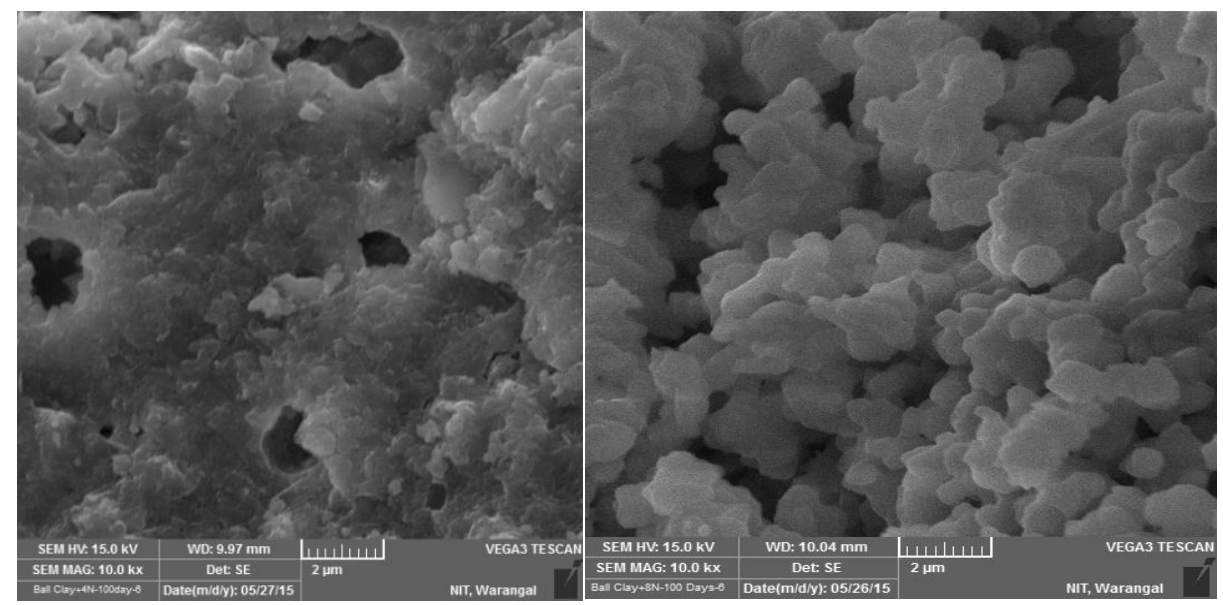

Fig. 7: SEM image of Ball clay under 100 days interaction (Pellet type).

Table 3: Summary of observed transmutations in contaminated ball clay.

\begin{tabular}{|llllll|}
\hline Pore fluid & Interaction period & Ball clay & Pore fluid & Interaction period & Ball clay \\
\hline Water & - & Quartz, Kaolinite & $4 \mathrm{~N}$ & 7 days & Quartz, Kaolinite \\
$0.1 \mathrm{~N}$ & 7 days & Quartz, Kaolinite & $\mathrm{NaOH}$ & 28 days & Quartz, Kaolinite, Sodalite, Natrite \\
$\mathrm{NaOH}$ & 28 days & Quartz, Kaolinite & & 100 days & Quartz, Sodalite, Natrite \\
& 100 days & Quartz, Kaolinite & & 7 days & Quartz, Kaolinite \\
$1 \mathrm{~N}$ & 7 days & Quartz, Kaolinite & $8 \mathrm{~N}$ & 28 days & Quartz, Sodalite, Natrite \\
$\mathrm{NaOH}$ & 28 days & Quartz, Kaolinite & $\mathrm{NaOH}$ & 100 days & Quartz, Sodalite, Cancrinite, Nitratine \\
& 100 days & Quartz, Kaolinite, Sodalite & & & \\
\hline
\end{tabular}

peaks pertaining to sodalite $(6.34,3.66$, and $2.82[\AA])$ - a sodium alumina silicate hydroxide hydrate. However, there is a complete dissolution of kaolinite minerals under $4 \mathrm{~N} \mathrm{NaOH}$ concentrations with strong peaks of sodalite and satrite (3.23, 2.96, 2.71, and $2.62[\AA]]$ ). Ball clay when it interacts with $8 \mathrm{~N} \mathrm{NaOH}$ concentration enhanced the formation of sodalite peaks with high intensities along with cancrinite $(6.32$, $2.42,1.42[\AA]$ ) and nitratine (sodium nitrate). Cancrinite which is identified in $8 \mathrm{~N} \mathrm{NaOH}$ also belongs to the zeolite group. Further, the XRD pattern of $8 \mathrm{~N} \mathrm{NaOH}$ highlights the maximum dissolution of strong peaks pertaining to quartz.

\section{Morphological Changes of Ball Clay under 100s Day Interaction period}

From SEM images of Fig. 7, it is clear that there are no specific morphological changes when Ball clay interacts with $0.1 \mathrm{~N} \mathrm{NaOH}$ for 100 days. A subtle change in texture is observed when the same Ball clay interacts with $1 \mathrm{~N} \mathrm{NaOH}$ with initial formations of sodalites. However, Ball clay exhibited drastic changes in its morphology when it interacts with $4 \mathrm{~N}$ and $8 \mathrm{~N} \mathrm{NaOH}$ solutions. Typical compacted pellet type morphology clearly reflects under $4 \mathrm{~N}$ concentration of $\mathrm{NaOH}$ indicating the complete dissolution of kaolinite minerals which triggers the formation of sodalite minerals. The micropores with specific sizes on the surface of the texture, confirm the cubic crystalline zeolitic formations. Moreover, cancrinite of zeolite group further made the morphology in $8 \mathrm{~N} \mathrm{NaOH}$ look more compact and denser with pellet type formations. The summary of transmutations of alkali contaminated Ball clay is highlighted in the conclusion under Table 3.

\section{CONCLUSION}

Under $0.1 \mathrm{~N}$ and $1 \mathrm{~N}$ concentrations of $\mathrm{NaOH}$ with 7 days of interactions, Ball clay exhibited low dissolution rates of alumina silicates. At a higher concentration (4N and $8 \mathrm{~N} \mathrm{NaOH}$ ) with short-term (7 days) interaction, Ball clay has not shown any significant changes in mineralogy and morphology. However, a higher rate of dissolution and precipitation of Ball clay are observed under $4 \mathrm{~N}$ and $8 \mathrm{~N}$ concentrations of $\mathrm{NaOH}$ with 100 days of interaction. Transformation of basic needle shape morphology into compacted pellets with open-type textural voids confirms the formations of sodium-based zeolite. 


\section{ACKNOWLEDGEMENTS}

We acknowledge and extend our regards to University Grands Commission (UGC) for sanctioning and supporting financially the UGC-Major Research Project, New Delhi, India, (File No.43-267/2014; dt:27.10.2017)

\section{REFERENCES}

Assa'ad, A. 1998. The differential upheaval of phosphoric acid storage tanks in Aqaba, Jordan. J. Perform. Constr. Facil. J., 12(2): 71-76.

ASTM E200-08, 2008. Standard Practice for Preparation, Standardization, and Storage of Standard and Reagent Solutions for Chemical Analysis. ASTM International, West Conshohocken, PA.

Barnes, M.C., Addai-Mensah, J. and Gerson, A.R. 1999. The mechanism of the sodalite-to-cancrinite phase transformation in synthetic spent Bayer liquor. Micro. and Meso. Mat., 31(3): 287-302.

Bauer, A. and Berger, G. 1998. Kaolinite and smectite dissolution rate in high molar $\mathrm{KOH}$ solutions at $35^{\circ}$ and $80^{\circ} \mathrm{C}$. Appl.Geochem., 13: 905-916.

Bauer, A. and Velde, B. 1999. Smectite transformation in high molar KOH solutions. Clay Min., 34: 259-273.

Chunikhin, V.G., Mavrodi, V.K.H., Kramarenko, O.A. and Dobromil'skaya, N.G. 1988. Effect of leakage of industrial alkali solutions on the construction properties of soils. Soil Mech. Found. Eng., 25(6): 559-561.
Cuadros, J. and Linares, J. 1996. Experimental kinetic study of the smectiteto-illite transformation. Geochim. Cosmochim. Acta., 60: 439-453.

Elert, K., Pardo, E.S. and Rodriguez-Navarro, C. 2015. Influence of organic matter on the reactivity of clay minerals in highly alkaline environments. Appl. Clay Sci., 111: 2- 36

Ibrahim, A.M. 2004. Soil pollution: Origin, Monitoring \& Remediation. Springer, New York.

Rao, S.M. and Rao, K.S. S. 1994. Ground heaving from caustic soda solution spillage: A case study, Soils Found., 34(2): 13-18.

Rao, S.M. and Sridharan, A. 1985. The mechanism controlling the volume change behavior of kaolinite. Clay. Clay Min., 33(4): 323-328.

Sibley, M.H. and Vadgama, N.J. 1986. Investigation of ground heave at ICI Mond division, Castner-Keller works, Runcorn. Geol. Society London. Eng. Geol., 2: 367-373

Sokolovich, V.E. 1995. Chemical heaving of soils. Soil Mech. Found. Eng., 32(4): 135-137.

Sokolovich, V.E. and Troitskii, G.M. 1976. The heaving of a sand base is a consequence of the development of secondary crystal hydrate formations. Soil Mech. Found. Eng., 13(6): 376-378.

Sivapullaiah, P.V., Allam, M.M. and Sankara, G. 2004. Structural distortion due to heaving of foundation soil induced by alkali contamination. Int. Conf. Struct. Found. Fail., 1: 601-611.

Taubald, H., Bauer, A., Schaefer, T., Satir, M. and Kim, J.I. 2000. Experimental investigation of the effect of high-pH solutions on the Opalinus shale and the Hammerschmiede smectite. Clay Min., 35: 515-524. 